\title{
Simulation of Plasmonics Nanodevices with Coupled Maxwell and Schrödinger Equations using the FDTD Method
}

\author{
Iftikhar Ahmed and Erping Li
}

\author{
Department of Electronics and Photonics \\ A*STAR, Institute of High Performance Computing, Singapore \\ *corresponding author, E-mail: iahmed@ihpc.a-star.edu.sg
}

\begin{abstract}
A nume rical a pproach that cou ples Loren tz-Drude model incorporated Maxwell equations with Schrödinger equation is presented for the simulation of pla smonics na nodevices. Maxwell equa tions w ith Lore ntz-Drude (LD ) dispersive model are a pplied to 1 arge size c omponents, $\mathrm{w}$ hereas coupled Maxwell and Schrödinger equations are applied to components where quantum effects a re needed. The finite difference time do main me thod (F DTD) is appl ied to simulate these coupled equations. Numerical re sults of the coupled ap proach are compared $\mathrm{w}$ ith th $\mathrm{e}$ conventional approach.
\end{abstract}

\section{Introduction}

The miniaturization of devices and high speed data are main challenges with existing silicon based technologies, and the reasons behind are diffraction $1 \mathrm{imit}$ and $\mathrm{R} \mathrm{C}$ time delay respectively. Fo $r$ the so lution of such challenges different efforts have been done in the past, how ever, an a rea known as plasmonics has been introduced recently to han dle them, and it has shown prom ising app lications [1-3]. Plasmonics deals $w$ ith co llective osci llation of fre e electr ons a $t \mathrm{t}$ he interface of dielectric and metal, which remain bounded to the surface. Plasmonics is generally categorized into surface plasmon pol aritons (S PP) and 1 ocalized surface plasmon resonance (LS PR). The $f$ irst one is mor e suitable for information transmission rela ted applications, w hile th e second one is preferable for se nsing ap plications. A w ide range of plasmonic devices have been simulated, fabricated and characterized [1-10]. Some interesting results show that the surface plasmon polariton has strong analogy to Young's double-slit experiment and is discussed in [4]. The concept of semiconductor plasmonics using a so lid state model that includes Pauli exculsion principle, state filling effect, FermiDirac $t$ hermalization, an d externa 1 magnetic fie $1 d$ is presented in [5]. A numerical approach that consists of solid state and Lorentz-Drude m odels is presented to simul ate active plasmonics devices [6]; and it is also used to simulate a plasm onic source, and $t$ hen 1 ight ex traction from $t$ he source [7]. S ome othe $r$ active plasmonic de vices such a $\mathrm{s}$ Plas-MOStor (pla smonic based trans istor), ultrafa st a ctive devices, pa ssive a nd ac tive photonics c ircuits using S PP have been reported in [8-10]. The concept of $r$ eplacing the conventional gold and silver with doped semiconductors and intermetallics has been discussed in [11].

Plasmonic bas ed phenomena have pote ntial t o ha ndle the challenges with existing CMOS and photonics technologies, and ca $\mathrm{n}$ be $\mathrm{u}$ sed to $\mathrm{i}$ nterface ph otonics a nd e lectronics devices e ffectively. H owever, m odeling and simulation of such in terfacing do mains become complex due to di fferent scales of components. These complexities can be solved by implying different techniques. Nonetheless, when the size of a device redu ces to a few nanom eters, quantum effec ts dominate a nd the ir c onsiderations become important to maintain the ac curacy. The refore, to incor porate them into modeling and simulation te chniques, modifications in the conventional numerical tec hniques ar e neede $\mathrm{d}$, w hereas conventional numerical techniques have performed well for the simulation of bulk materials and devices.

For quantum effects there is need to adopt some appropriate approaches from qua ntum $\mathrm{m}$ echanics, a nd usually Schrödinger equa tion is c onsidered to incorporate su ch effects. On the other hand Maxwell equations are used for electromagnetic effec ts. Therefore, these equa tions are coupled to simulate those a pplications in w hich combined effects are needed [12-13]. In [12] a hybrid transmission line matrix ( TLM) [14] and FDTD [15], and in [13] a hybrid locally one dimensional (LO D)-FDTD [16] and F DTD methods are applied to coupled non-dispersive Maxwell and Schrödinger equations. In [12] the FDTD method is applied to Schrödinger equation to simu late ca rbon nanotube while the TL $\mathrm{M}$ metho $\mathrm{d}$ is applied to $\mathrm{t}$ he conventional $\mathrm{n}$ ondispersive Ma xwell e quations to simula te the $r$ est of the structure. Whereas in [13], the FDTD method is ap plied to Schrödinger equation to simulate a semiconductor nanowire and the LOD-FDTD method is applied to the conventional non-dispersive Maxw ell e quations to simulate rest of $t$ he structure effi ciently. In brief, in [12-13] hybrid ap proaches are a pplied $t$ o na notube, nan owire and non $\mathrm{d}$ ispersive materials.

In this paper, as compared to the [12-13], the LD dispersive model [17] i ncorporated Maxwell equa tions are coup led with $\mathrm{S}$ chrödinger equa tion $\mathrm{t}$ o sim ulate $\mathrm{pl}$ asmonic nanodevices. Schrödinger e quation i ncorporated Maxw ell equations are applied to simulate the components in which quantum effects are needed. The FDTD method is applied to simulate the se coup led equ ations. In sect ion 2, deta iled 
formulation of the Ma xwell eq uations w ith LD mode 1, formulation of the $\mathrm{S}$ chrödinger equation in the presence of external elec tromagnetic fie ld, and di scretization us ing the FDTD method are presented. The reason of using LD model as compared to the other dispersive models is because of its better accuracy for broader range of wavelength. In section 3 , num erical re sults of the coupled approach are compared with those from the conventional Maxwell approach and at the end conclusion is given.

\section{Formulations}

The time de pendent Maxw ell e quations w ith freque ncy dependent permittivity a nd quantum cur rent de nsity are written as

$\mu \frac{\partial \mathrm{H}}{\partial \mathrm{t}}=-\nabla \times \mathrm{E}$

$\varepsilon(\omega) \frac{\partial \mathrm{E}}{\partial \mathrm{t}}=\nabla \times \mathrm{H}-\mathrm{J}_{\mathrm{q}}$

where $\mathrm{J}_{\mathrm{q}}$ is quantum current density, and is obtained from Schrödinger equa tion. $\varepsilon(\omega)=\varepsilon_{0} \varepsilon_{\mathrm{r}}(\omega)$ is the frequency dependent permittivity and is obtained from Lorentz-Drude dispersive m odel. In the model, D rude pa rt dea ls with intraband effe cts an $d$ is gen erally used fo $r$ fre e electr ons, whereas, the Lorentz model deals with interband effects and generally dea ls w ith bo unded electrons. The LD model is written as

$$
\varepsilon_{\mathrm{r}}(\omega)=\varepsilon_{\infty}+\frac{\omega_{\mathrm{pD}}^{2}}{\mathrm{j}^{2} \omega^{2}+\mathrm{j} \Gamma_{\mathrm{D}} \omega}+\frac{\Delta \varepsilon_{\mathrm{L}} \omega_{\mathrm{pL}}^{2}}{\mathrm{j}^{2} \omega^{2}+\mathrm{j} \omega \Gamma_{\mathrm{L}}+\omega_{\mathrm{L}}^{2}}
$$

where $\omega_{\mathrm{pD}}$ is plas ma fre quency a nd $\Gamma_{\mathrm{D}}$ is damping constant assoc iated $\mathrm{w}$ ith $\mathrm{D}$ rude mode 1 (intr aband e ffects) , $\omega_{\mathrm{pL}}$ is plasm a fr equency, $\Gamma_{\mathrm{L}}$ is da mping c onstant, a nd $\omega_{L}$ is resona nce fre quency of the first $p$ ole of Lore $n t z$ model (interband effects). After pu tting equation (3) in to equation (2) and by using the auxiliary differential equation (ADE) approach, and some mathematical simplifications we get following equations

$$
\begin{aligned}
& \nabla \times \mathrm{H}=\varepsilon_{0} \varepsilon_{\infty} \frac{\partial \mathrm{E}}{\partial \mathrm{t}}+\mathrm{Q}+\frac{\varepsilon_{0} \partial \mathrm{P}}{\partial \mathrm{t}}+\mathrm{J}_{\mathrm{q}} \\
& \frac{\partial \mathrm{Q}}{\partial \mathrm{t}}=\omega_{\mathrm{pD}}^{2} \varepsilon_{0} \mathrm{E}-\mathrm{Q} \Gamma_{\mathrm{D}} \\
& \frac{\partial^{2} \mathrm{P}}{\partial \mathrm{t}^{2}}+\Gamma_{\mathrm{L}} \frac{\partial \mathrm{P}}{\partial \mathrm{t}}+\omega_{\mathrm{L}}^{2} \mathrm{P}=\Delta \varepsilon_{\mathrm{L}} \omega_{\mathrm{pL}}^{2} \mathrm{E}
\end{aligned}
$$

Where terms with subscript D and term Q denote Drude model and terms with subscript $\mathrm{L}$ and term $\mathrm{P}$ denote Lorentz model. D uring the simu lation of a struct ure $w$ ith $t$ he proposed a pproach four different sc enarios can a rise i) a section of th e struc ture in $w$ hich there is no nee $d$ of dispersive model and quantum current density, ii) a region in which quantum current density is required but not dispersive model, iii) a section in which dispersive model is needed but not quantum current density, iv) a re gion where both effects are ne eded. Under all the se sce narios equa tion (2) w ill be effected. In this section, as an exam ple formulation for the scenario (iv) is presented, however, it can be modified based on the situation.

After some mathematical simplifications equation (4) can be written as

$$
\begin{aligned}
& \frac{\partial \mathrm{E}_{\mathrm{x}}}{\partial \mathrm{t}}=\frac{1}{\varepsilon_{0} \varepsilon_{\infty}}\left(\frac{\partial \mathrm{H}_{\mathrm{z}}}{\partial \mathrm{y}}-\frac{\partial \mathrm{H}_{\mathrm{y}}}{\partial \mathrm{z}}\right)-\frac{\mathrm{Q}_{\mathrm{x}}}{\varepsilon_{0} \varepsilon_{\infty}}-\frac{1}{\varepsilon_{\infty}} \frac{\partial \mathrm{P}_{\mathrm{x}}}{\partial \mathrm{t}}-\frac{1}{\varepsilon_{0} \varepsilon_{\infty}} \mathrm{J}_{\mathrm{qx}}(7) \\
& \frac{\partial \mathrm{E}_{\mathrm{y}}}{\partial \mathrm{t}}=\frac{1}{\varepsilon_{0} \varepsilon_{\infty}}\left(\frac{\partial \mathrm{H}_{\mathrm{x}}}{\partial \mathrm{z}}-\frac{\partial \mathrm{H}_{\mathrm{z}}}{\partial \mathrm{x}}\right)-\frac{\mathrm{Q}_{\mathrm{y}}}{\varepsilon_{0} \varepsilon_{\infty}}-\frac{1}{\varepsilon_{\infty}} \frac{\partial \mathrm{P}_{\mathrm{y}}}{\partial \mathrm{t}}-\frac{1}{\varepsilon_{0} \varepsilon_{\infty}} \mathrm{J}_{\mathrm{qy}}(8) \\
& \frac{\partial \mathrm{E}_{\mathrm{z}}}{\partial \mathrm{t}}=\frac{1}{\varepsilon_{0} \varepsilon_{\infty}}\left(\frac{\partial \mathrm{H}_{\mathrm{y}}}{\partial \mathrm{x}}-\frac{\partial \mathrm{H}_{\mathrm{x}}}{\partial \mathrm{y}}\right)-\frac{\mathrm{Q}_{\mathrm{z}}}{\varepsilon_{0} \varepsilon_{\infty}}-\frac{1}{\varepsilon_{\infty}} \frac{\partial \mathrm{P}_{\mathrm{z}}}{\partial \mathrm{t}}-\frac{1}{\varepsilon_{0} \varepsilon_{\infty}} \mathrm{J}_{\mathrm{qz}}(9) \\
& \frac{\partial \mathrm{H}_{\mathrm{x}}}{\partial \mathrm{t}}=\frac{1}{\mu}\left(\frac{\partial \mathrm{E}_{\mathrm{y}}}{\partial \mathrm{z}}-\frac{\partial \mathrm{E}_{\mathrm{z}}}{\partial \mathrm{y}}\right) \\
& \frac{\partial \mathrm{H}_{\mathrm{y}}}{\partial \mathrm{t}}=\frac{1}{\mu}\left(\frac{\partial \mathrm{E}_{\mathrm{z}}}{\partial \mathrm{x}}-\frac{\partial \mathrm{E}_{\mathrm{x}}}{\partial \mathrm{z}}\right) \\
& \frac{\partial \mathrm{H}_{\mathrm{z}}}{\partial \mathrm{t}}=\frac{1}{\mu}\left(\frac{\partial \mathrm{E}_{\mathrm{x}}}{\partial \mathrm{y}}-\frac{\partial \mathrm{E}_{\mathrm{y}}}{\partial \mathrm{x}}\right)
\end{aligned}
$$

The discritized form of the equations (7) to (9) is given as

$$
\begin{aligned}
& E_{x}^{n+1}\left(i+\frac{1}{2}, j, k\right)=\frac{1}{\Omega_{x}} E_{x}{ }^{n}\left(i+\frac{1}{2}, j, k\right) \\
& +\frac{\Delta t}{\Omega_{x} \varepsilon_{0} \varepsilon_{\infty}}\left[\frac{H_{z}^{n+\frac{1}{2}}\left(i+\frac{1}{2}, j+\frac{1}{2}, k\right)-H_{z}^{n+\frac{1}{2}}\left(i+\frac{1}{2}, j-\frac{1}{2}, k\right)}{\Delta y}\right] \\
& -\frac{\Delta t}{2 \Omega_{x} \varepsilon_{0} \varepsilon_{\infty}}\left[\begin{array}{l}
H_{y}^{n+\frac{1}{2}}\left(i+\frac{1}{2}, j, k+\frac{1}{2}\right)-H_{y}^{n+\frac{1}{2}}\left(i+\frac{1}{2}, j, k-\frac{1}{2}\right) \\
\left.-Q_{x}^{n} Q_{x}^{n}\left(i+\frac{1}{2}, j, k\right)+\beta_{x} E_{x}^{n}\left(i+\frac{1}{2}, j, k\right)\right]
\end{array}\right] \\
& -\frac{1}{\Omega_{x} \varepsilon_{\infty}}\left[-\rho_{x} P_{x}^{n-1}\left(i+\frac{1}{2}, j, k\right)-P_{x}^{n}\left(i+\frac{1}{2}, j, k\right)\right]
\end{aligned}
$$




$$
\begin{aligned}
& E_{y}^{n+1}\left(i, j+\frac{1}{2}, k\right)=\frac{1}{\Omega_{y}} E_{y}{ }^{n}\left(i, j+\frac{1}{2}, k\right)
\end{aligned}
$$

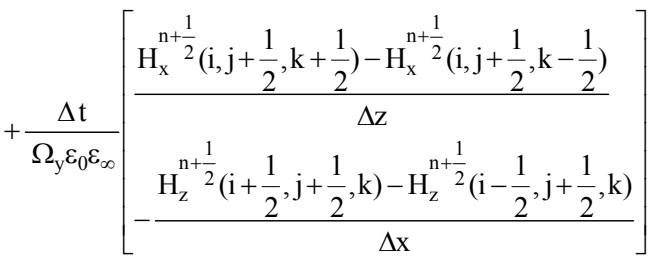

$$
\begin{aligned}
& -\frac{\Delta t}{2 \Omega_{y} \varepsilon_{0} \varepsilon_{\infty}}\left[\begin{array}{l}
\alpha_{y} Q_{y}^{n}\left(i, j+\frac{1}{2}, k\right)+\beta_{y} E_{y}^{n}\left(i, j+\frac{1}{2}, k\right) \\
+Q_{y}^{n}\left(i, j+\frac{1}{2}, k\right)
\end{array}\right] \\
& -\frac{1}{\Omega_{y} \varepsilon_{\infty}}\left[\begin{array}{c}
\varsigma_{y} E_{y}{ }^{n}\left(i, j+\frac{1}{2}, k\right)+\tau_{y} P_{y}^{n}\left(i, j+\frac{1}{2}, k\right) \\
-\rho_{y} P_{y}^{n-1}\left(i, j+\frac{1}{2}, k\right)-P_{y}^{n}\left(i, j+\frac{1}{2}, k\right)
\end{array}\right]-\frac{1}{\varepsilon_{0} \varepsilon_{\infty}} J_{q y}^{n+1}(r) \\
& E_{z}^{n+1}\left(i, j, k+\frac{1}{2}\right)=\frac{1}{\Omega_{z}} E_{z}^{n}\left(i, j, k+\frac{1}{2}\right)
\end{aligned}
$$

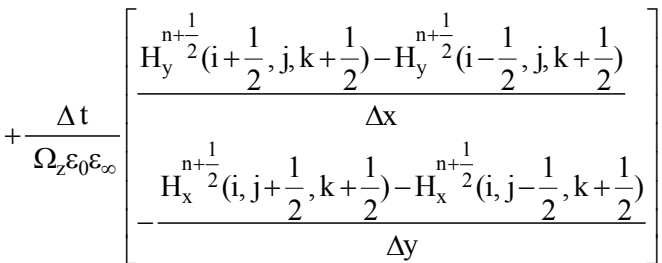

$$
\begin{aligned}
& -\frac{\Delta \mathrm{t}}{2 \Omega_{\mathrm{z}} \varepsilon_{0} \varepsilon_{\infty}}\left[\begin{array}{l}
\alpha_{\mathrm{z}} \mathrm{Q}_{\mathrm{z}}^{\mathrm{n}}\left(\mathrm{i}, \mathrm{j}, \mathrm{k}+\frac{1}{2}\right)+\beta_{\mathrm{z}} \mathrm{E}_{\mathrm{z}}^{\mathrm{n}}\left(\mathrm{i}, \mathrm{j}, \mathrm{k}+\frac{1}{2}\right) \\
+\mathrm{Q}_{\mathrm{z}}^{\mathrm{n}}\left(\mathrm{i}, \mathrm{j}, \mathrm{k}+\frac{1}{2}\right)
\end{array}\right] \\
& -\frac{1}{\Omega_{\mathrm{z}} \varepsilon_{\infty}}\left[\begin{array}{c}
\varsigma_{\mathrm{z}} \mathrm{E}_{\mathrm{z}}^{\mathrm{n}}\left(\mathrm{i}, \mathrm{j}, \mathrm{k}+\frac{1}{2}\right)+\tau_{\mathrm{z}} \mathrm{P}_{\mathrm{z}}^{\mathrm{n}}\left(\mathrm{i}, \mathrm{j}, \mathrm{k}+\frac{1}{2}\right) \\
-\rho_{\mathrm{z}} \mathrm{P}_{\mathrm{z}}^{\mathrm{n}-1}\left(\mathrm{i}, \mathrm{j}, \mathrm{k}+\frac{1}{2}\right)-\mathrm{P}_{\mathrm{z}}^{\mathrm{n}}\left(\mathrm{i}, \mathrm{j}, \mathrm{k}+\frac{1}{2}\right)
\end{array}\right]-\frac{1}{\varepsilon_{0} \varepsilon_{\infty}} \mathrm{J}_{\mathrm{qz}}^{\mathrm{n}+1}(\mathrm{r})
\end{aligned}
$$

Equations (5) and (6) are discritzed as

$$
\begin{aligned}
& \left.Q_{r}^{n+1}=\alpha_{r} Q_{r}^{n}+\beta_{r} \mid E_{r}^{n+1}+E_{r}^{n}\right\rfloor \\
& P_{r}^{n+1}=\varsigma_{r}\left(E_{r}^{n+1}+E_{r}^{n}\right)+\tau_{r} P_{r}^{n}-\rho_{r} P_{r}^{n-1}
\end{aligned}
$$

where

$$
\begin{aligned}
& \alpha_{\mathrm{r}}=\frac{\left(1-\frac{\Delta \mathrm{t} \Gamma_{\mathrm{D}}}{2}\right)}{\left(1+\frac{\Delta \mathrm{t} \Gamma_{\mathrm{D}}}{2}\right)}, \beta_{\mathrm{r}}=\frac{\frac{\Delta \mathrm{t} \omega_{\mathrm{pD}}^{2} \varepsilon_{0}}{2}}{\left(1+\frac{\Delta \mathrm{t} \Gamma_{\mathrm{D}}}{2}\right)}, \Omega_{\mathrm{r}}=\left(\frac{\varsigma_{\mathrm{r}}}{\varepsilon_{\infty}}+1+\frac{\Delta \mathrm{t} \beta_{\mathrm{r}}}{2 \varepsilon_{0} \varepsilon_{\infty}}\right) \\
& \varsigma_{\mathrm{r}}=\frac{\frac{\Delta \mathrm{t}^{2} \Delta \varepsilon_{\mathrm{L}} \omega_{\mathrm{pL}}^{2}}{2}}{\left(1+\Delta \mathrm{t} \Gamma_{\mathrm{L}}+\frac{\Delta \mathrm{t}^{2}}{2} \omega_{\mathrm{L}}^{2}\right)}, \tau_{\mathrm{r}}=\frac{\left(2+\Delta \mathrm{t} \Gamma_{\mathrm{L}}-\frac{\Delta \mathrm{t}^{2}}{2} \omega_{\mathrm{L}}^{2}\right)}{\left(1+\Delta \mathrm{t} \Gamma_{\mathrm{L}}+\frac{\Delta \mathrm{t}^{2}}{2} \omega_{\mathrm{L}}^{2}\right)} \\
& \rho_{\mathrm{r}}=\frac{1}{\left(1+\Delta \mathrm{t} \Gamma_{\mathrm{L}}+\frac{\Delta \mathrm{t}^{2}}{2} \omega_{\mathrm{L}}^{2}\right)}
\end{aligned}
$$

where $\mathrm{r}=\mathrm{x}, \mathrm{y}$ and $\mathrm{z}$.

Equations (10) to (12) are similar to conventional magnetic field equations in FDTD method and are discritized as

$$
\begin{aligned}
& \mathrm{H}_{\mathrm{x}}{ }^{\mathrm{n}+\frac{1}{2}}\left(\mathrm{i}, \mathrm{j}+\frac{1}{2}, \mathrm{k}+\frac{1}{2}\right)=\mathrm{H}_{\mathrm{x}}{ }^{\mathrm{n}-\frac{1}{2}}\left(\mathrm{i}, \mathrm{j}+\frac{1}{2}, \mathrm{k}+\frac{1}{2}\right)
\end{aligned}
$$

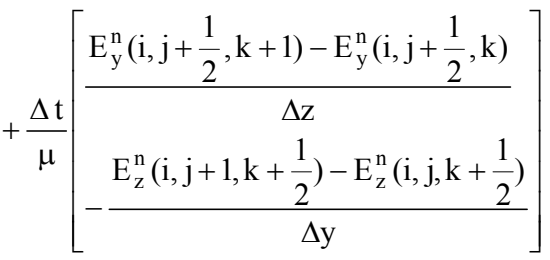

$$
\begin{aligned}
& \mathrm{H}_{\mathrm{y}}{ }^{\mathrm{n}+\frac{1}{2}}\left(\mathrm{i}+\frac{1}{2}, \mathrm{j}, \mathrm{k}+\frac{1}{2}\right)=\mathrm{H}_{\mathrm{y}}{ }^{\mathrm{n}-\frac{1}{2}}\left(\mathrm{i}+\frac{1}{2}, \mathrm{j}, \mathrm{k}+\frac{1}{2}\right)
\end{aligned}
$$

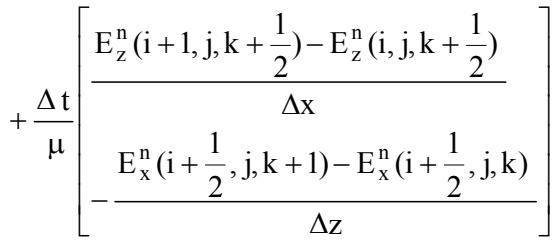$$
\mathrm{H}_{\mathrm{z}}{ }^{\mathrm{n}+\frac{1}{2}}\left(\mathrm{i}+\frac{1}{2}, \mathrm{j}+\frac{1}{2}, \mathrm{k}\right)=\mathrm{H}_{\mathrm{z}}{ }^{\mathrm{n}-\frac{1}{2}}\left(\mathrm{i}+\frac{1}{2}, \mathrm{j}+\frac{1}{2}, \mathrm{k}\right)+
$$

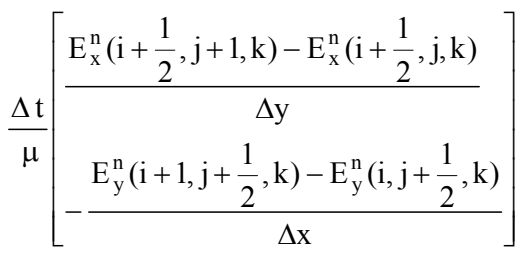

Equations ( 13) to ( 20) $\mathrm{r}$ epresent $\mathrm{d}$ iscritized form of $\mathrm{t}$ he Maxwell equations (equation 13 to 15 with LD model and quantum current density) after applying the FDTD method. For quan tum effects the ti me de pendent $S$ chrödinger equation is con sidered in the pr esence of e xternal electromagnetic field and is written as

$\mathrm{i} \hbar \frac{\partial \Psi(\mathrm{r}, \mathrm{t})}{\partial \mathrm{t}}=\left[\frac{1}{2 \mathrm{~m}}[-\mathrm{i} \hbar \nabla-\mathrm{qA}(\mathrm{r}, \mathrm{t})]^{2}+\mathrm{q} \Phi(\mathrm{r}, \mathrm{t})+\mathrm{V}(\mathrm{r})\right] \Psi(\mathrm{r}, \mathrm{t})$

where $\Psi$ is wavefunction, A is vector potential, $\Phi$ is scalar potential, $\hbar=\mathrm{h} / 2 \pi, \mathrm{h}$ is Planck constant, $\mathrm{q}$ is charge, $\mathrm{m}$ is mass of an ele ctron and $r$ repr esents spatial variables $x, y$, and $\mathrm{z}$. The ve ctor and sca lar poten tials are obtai ned from following equations

$$
\mathrm{E}=-\frac{\partial \mathrm{A}}{\partial \mathrm{t}}-\nabla . \Phi \quad, \quad \mathrm{H}=\frac{1}{\mu} \nabla \times \mathrm{A}
$$

The eq uation (21) is co mplex, and by using $t$ he relation $\Psi(\mathrm{r}, \mathrm{t})=\Psi_{\mathrm{R}}(\mathrm{r}, \mathrm{t})+\mathrm{i} \Psi_{\mathrm{I}}(\mathrm{r}, \mathrm{t})$ and a fter some simplifications; it is separated into real and imaginary parts and is given as 


$$
\begin{aligned}
& \frac{\partial \Psi_{\mathrm{R}}(\mathrm{r}, \mathrm{t})}{\partial \mathrm{t}}=-\frac{\hbar}{2 \mathrm{~m}} \frac{\partial^{2} \Psi_{\mathrm{I}}(\mathrm{r}, \mathrm{t})}{\partial \mathrm{r}^{2}}+\frac{\mathrm{q}^{2}}{2 \hbar \mathrm{m}}(\mathrm{A}(\mathrm{r}, \mathrm{t}))^{2} \Psi_{\mathrm{I}}(\mathrm{r}, \mathrm{t}) \\
& -\frac{\mathrm{q}}{2 \mathrm{~m}} \frac{\partial \mathrm{A}(\mathrm{r}, \mathrm{t})}{\partial \mathrm{r}} \Psi_{\mathrm{R}}(\mathrm{r}, \mathrm{t})-\frac{\mathrm{q}}{\mathrm{m}} \mathrm{A}(\mathrm{r}, \mathrm{t}) \frac{\partial \Psi_{\mathrm{R}}(\mathrm{r}, \mathrm{t})}{\partial \mathrm{r}}-\frac{\mathrm{q}}{\hbar} \Phi(\mathrm{r}, \mathrm{t}) \Psi_{\mathrm{I}}(\mathrm{r}, \mathrm{t}) \\
& +\frac{1}{\hbar} \mathrm{V}(\mathrm{r}) \Psi_{\mathrm{I}}(\mathrm{r}, \mathrm{t}) \\
& \frac{\partial \Psi_{\mathrm{I}}(\mathrm{r}, \mathrm{t})}{\partial \mathrm{t}}=\frac{\hbar}{2 \mathrm{~m}} \frac{\partial^{2} \Psi_{\mathrm{R}}(\mathrm{r}, \mathrm{t})}{\partial \mathrm{r}^{2}}-\frac{\mathrm{q}^{2}}{2 \hbar \mathrm{m}}(\mathrm{A}(\mathrm{r}, \mathrm{t}))^{2} \Psi_{\mathrm{R}}(\mathrm{r}, \mathrm{t}) \\
& -\frac{\mathrm{q}}{2 \mathrm{~m}} \frac{\partial \mathrm{A}(\mathrm{r}, \mathrm{t})}{\partial \mathrm{r}} \Psi_{\mathrm{I}}(\mathrm{r}, \mathrm{t})-\frac{\mathrm{q}}{\mathrm{m}} \mathrm{A}(\mathrm{r}, \mathrm{t}) \frac{\partial \Psi_{\mathrm{I}}(\mathrm{r}, \mathrm{t})}{\partial \mathrm{r}}+\frac{\mathrm{q}}{\hbar} \Phi(\mathrm{r}, \mathrm{t}) \Psi_{\mathrm{R}}(\mathrm{r}, \mathrm{t}) \\
& -\frac{1}{\hbar} \mathrm{V}(\mathrm{r}) \Psi_{\mathrm{R}}(\mathrm{r}, \mathrm{t})
\end{aligned}
$$

Temporal discretization of equations (22) and (23) is given as

$$
\begin{aligned}
& \Psi_{\mathrm{R}}^{\mathrm{n}+1}(\mathrm{r})=\Psi_{\mathrm{R}}^{\mathrm{n}}(\mathrm{r})-\frac{\hbar \Delta \mathrm{t}}{2 \mathrm{~m}} \frac{\partial^{2} \Psi_{\mathrm{I}}^{\mathrm{n}}(\mathrm{r})}{\partial \mathrm{r}^{2}}+\frac{\mathrm{q}^{2} \Delta \mathrm{t}}{2 \hbar \mathrm{m}}\left(\mathrm{A}^{\mathrm{n}}(\mathrm{r})\right)^{2} \Psi_{I}^{\mathrm{n}}(\mathrm{r}) \\
& -\frac{\mathrm{q} \Delta \mathrm{t}}{2 \mathrm{~m}} \frac{\partial \mathrm{A}^{\mathrm{n}}(\mathrm{r})}{\partial \mathrm{r}} \Psi_{\mathrm{R}}^{\mathrm{n}}(\mathrm{r})-\frac{\mathrm{q} \Delta \mathrm{t}}{\mathrm{m}} \mathrm{A}^{\mathrm{n}}(\mathrm{r}) \frac{\partial \Psi_{\mathrm{R}}^{\mathrm{n}}(\mathrm{r})}{\partial \mathrm{r}} \\
& -\frac{\mathrm{q} \Delta \mathrm{t}}{\hbar} \Phi^{\mathrm{n}}(\mathrm{r}) \Psi_{I}^{\mathrm{n}}(\mathrm{r})+\frac{\Delta \mathrm{t}}{\hbar} \mathrm{V}(\mathrm{r}) \Psi_{\mathrm{I}}^{\mathrm{n}}(\mathrm{r}) \\
& \Psi_{\mathrm{I}}^{\mathrm{n}+1}(\mathrm{r})=\Psi_{\mathrm{I}}^{\mathrm{n}}(\mathrm{r})-\frac{\hbar \Delta \mathrm{t}}{2 \mathrm{~m}} \frac{\partial^{2} \Psi_{\mathrm{R}}^{\mathrm{n}}(\mathrm{r})}{\partial \mathrm{r}^{2}}+\frac{\mathrm{q}^{2} \Delta \mathrm{t}}{2 \hbar \mathrm{m}}\left(\mathrm{A}^{\mathrm{n}}(\mathrm{r})\right)^{2} \Psi_{\mathrm{R}}^{\mathrm{n}}(\mathrm{r}) \\
& -\frac{\mathrm{q} \Delta \mathrm{t}}{2 \mathrm{~m}} \frac{\partial \mathrm{A}^{\mathrm{n}}(\mathrm{r})}{\partial \mathrm{r}} \Psi_{\mathrm{I}}^{\mathrm{n}}(\mathrm{r})-\frac{\mathrm{q} \Delta \mathrm{t}}{\mathrm{m}} \mathrm{A}^{\mathrm{n}}(\mathrm{r}) \frac{\partial \Psi_{I}^{\mathrm{n}}(\mathrm{r})}{\partial \mathrm{r}} \\
& -\frac{\mathrm{q} \Delta \mathrm{t}}{\hbar} \Phi^{\mathrm{n}}(\mathrm{r}) \Psi_{\mathrm{R}}^{\mathrm{n}}(\mathrm{r})+\frac{\Delta \mathrm{t}}{\hbar} \mathrm{V}(\mathrm{r}) \Psi_{\mathrm{R}}^{\mathrm{n}}(\mathrm{r})
\end{aligned}
$$

After calc ulating $t$ he re al and im aginary pa rts of th e wavefunction, and then by using the following relation, the quantum current density is obtained.

$$
\mathrm{J}_{\mathrm{q}}^{\mathrm{n}+1}(\mathrm{r})=\frac{\hbar \mathrm{q}}{2 \mathrm{im}}\left(\begin{array}{c}
\Psi^{\mathrm{n}+1^{*}}(\mathrm{r}) \frac{\partial \Psi^{\mathrm{n}+1}(\mathrm{r})}{\partial \mathrm{r}} \\
-\Psi^{\mathrm{n}+1}(\mathrm{r}) \frac{\partial \Psi^{\mathrm{n}+1^{*}}(\mathrm{r})}{\partial \mathrm{r}}
\end{array}\right)-\frac{\mathrm{q}^{2}}{\mathrm{~m}}\left|\Psi^{\mathrm{n}+1}(\mathrm{r})\right|^{2} \mathrm{~A}^{\mathrm{n}+1}(\mathrm{r})
$$

Spatial d iscretization o fequa tions (24-26) an $\mathrm{dt}$ he corresponding term $\mathrm{J}_{\mathrm{q}}^{\mathrm{n}+1}(\mathrm{r})$ in equations (13-15) depends on the user how he/she w ant to implement these equations in one dimensional or three dimensional fashions. The meshing interface between Maxwell and Schrödinger equations also depends on o ne or three dimensional patter $n$ of spat ial discretization. We have used bot $h$ patterns a nd found the similar $r$ esults. For i nterface be tween Maxw ell and Schrödinger e quations, $\mathrm{w}$ ave function, quantum curr ent density and the corresponding electric field are discretized at same poin $t$. The val ue o fquan tum current dens ity at interface or boundary of $b$ oth d omains is adde $d$ up w ith electric fie ld. In other words, the qua ntum cur rent den sity can also be used as a source for the Maxwell equations i.e. at the $b$ oundary of Schrödinger equat ion, quan tum curr ent density is injected in to Maxwell equations. The vec tor and scalar potentials are $\mathrm{u}$ sed $\mathrm{t}$ o i ncorporate the e xternal electromagnetic fiel $\mathrm{d}$ i nto $\mathrm{S}$ chrödinger equat ion along the nanowire. In the simulation procedure, the magnetic field is updated first, the $\mathrm{n} v$ ector $\mathrm{p}$ otential, scalar pot ential, wave function, quan tum cur rent d ensity, and a the e nd ele ctric field are updated and this sequence continues, until the last iteration.

\section{Numerical Results}

For num erical results two different exa mples that inc lude dispersive and quan tum effe cts are st udied. A generalized structure i s show $\mathrm{n}$ in $\mathrm{F}$ ig. 1, in which sem iconductor nanowires are use $\mathrm{d}$ as inter connects be tween $\mathrm{p}$ lasmonics nanodevices. The size of plasmonics de vices $\mathrm{c}$ an be from few nanometer to few hundred nanometers, whereas the size of inter connects ca $\mathrm{n}$ be few $\mathrm{n}$ anometers. For such applications in the pa per we use LD dispersive model for large si ze c omponents, w hereas $\mathrm{S}$ chrödinger eq uation is used for quantum effects needed region.

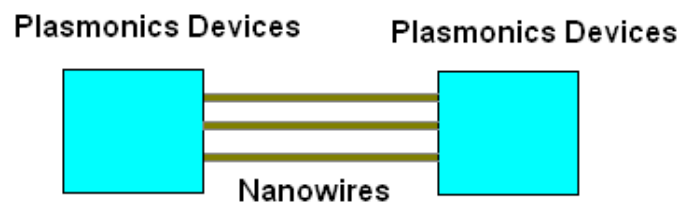

Fig. 1: A ge neralized st ructure for c oupled approach, in which plasmonics devices are interconnected via nanowires.

The structures studied in the paper have operating concept similar to $t$ he generalized struc ture in $\mathrm{F}$ ig. 1 . The structure for the first example is shown in Fig. 2(a). It consists of two gold nanospheres, each with a radius of $20 \mathrm{~nm}$, with a gap of $10 \mathrm{~nm}$ in between them, and a $2 \mathrm{~nm}$ thick and $70 \mathrm{~nm}$ long semiconductor nanowire $(\mathrm{NW})$ is plac ed a $\mathrm{t}$ center in between na nospheres. The purpose of the struct ure is to study $\mathrm{t}$ he qua ntum effec ts and then comparison o $\mathrm{ft}$ he coupled and conventional approaches. The cell size in each direction is uniform i.e. $2 \mathrm{~nm}$. To maintain the stability of the Schrödinger equation with the FDTD method, the time step should be smaller than the C ourant F riedrich Le vy (CFL) limit of Maxwell equations [18]. Therefore, in the coupled approach, the time step of the Schrödinger equation is taken as the time step for whole simulation domain. We take time step 100 times sm aller $t$ han $t$ hat of the CLN limit to accommodate the NW, in other words, accuracy will also be better if the cell size is smaller. We have checked method with $d$ ifferent grids or cell s izes and it is found that the proposed approach converges properly and in addition there is $n$ o sta bility issue, a s long a s the ti me step for $t$ he simulation domain is same as of Schrödinger equation. The parameters used for dispersive model are same as gi ven in [17]. The surrounding medium of the structure is free space. A Gaussian pulse is used as a source to get field localization in between nanospheres and a Gaussian pulse at NW is used to excite the $\mathrm{w}$ avefunction. F our diffe rent field e xcitation scenarios may arise during the simulation of the structure, I) excitation th at ca $\mathrm{n} g$ enerate $\mathrm{f}$ ield localization $\mathrm{b}$ etween nanospheres, II) source abo ve or below the $\mathrm{N} \mathrm{W}$ in the 
surrounding medium, III) use of qua ntum current density as a sour ce, IV) combination of the abo ve $t$ hree sc enarios. Figure 2 (b) shows snapshot of field localization in between nanospheres without having the NW in the $x y \mathrm{pl}$ ane, whereas Fig. 2 (c) depicts the snapshot of the total electric field inte nsity in the $x y \mathrm{p}$ lane with $\mathrm{n}$ anowire. Th ese both snapshots are obtained at steady state. In this application the excitation scenario (I) is used. Results show that most of the field is con fined along the NW. Figure 2(d) show s the field intensity with and without Schrödinger equation with respect to number of time steps and depicts the difference between both circumstances. Figure 2 (e) is plo tted with re spect to energy $(\mathrm{eV}) \mathrm{w}$ ith an $\mathrm{d} w$ ithout qua ntum effects. The difference of $0.16 \mathrm{e} \mathrm{V}$ i s o bserved. The field ob servation point is at $26 \mathrm{~nm}$ away from the center of nanospheres and $12 \mathrm{~nm} 1$ eft from the c enter of the NW. The se re sults illustrate the c lear diffe rence be tween coupled a nd conventional appr oaches. The possible reason of the difference between the resul ts of bo th appr oaches is quantum effect. Because in the case of co upled approach, the quantum current density takes into account, kine tic and potential energies of elec trons, vector and scalar potentials. Inclusion of these fa ctors i s ca use of shift i $\mathrm{n}$ t he fie ld intensity in Fig. 2 ( $d$ and e). It is also observed that if the structure is made of $\mathrm{b}$ ulk $\mathrm{m}$ aterials, then there is no difference in the numerical results of both approaches, and it is validation of the proposed approach.

The structure of sec ond example is shown in Fig. 3 (a), in which two pairs of gold nanospheres are placed at both ends of the nanowire. The thickness and length of the NW, radius and distance be tween nanospheres is same as in example 1 at first, however, latter on the distance between nanospheres is varied.

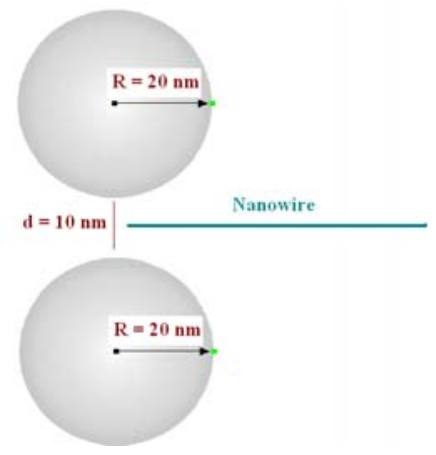

(a)

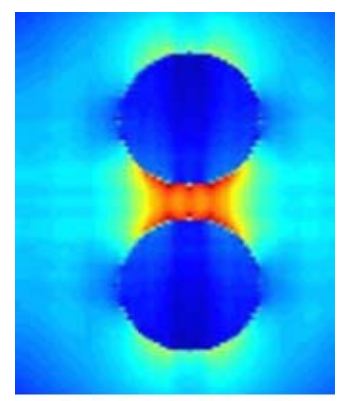

(b)

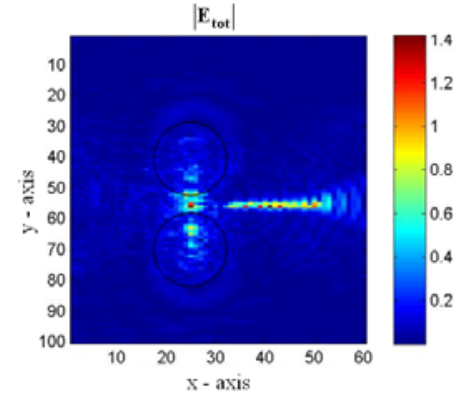

(c)

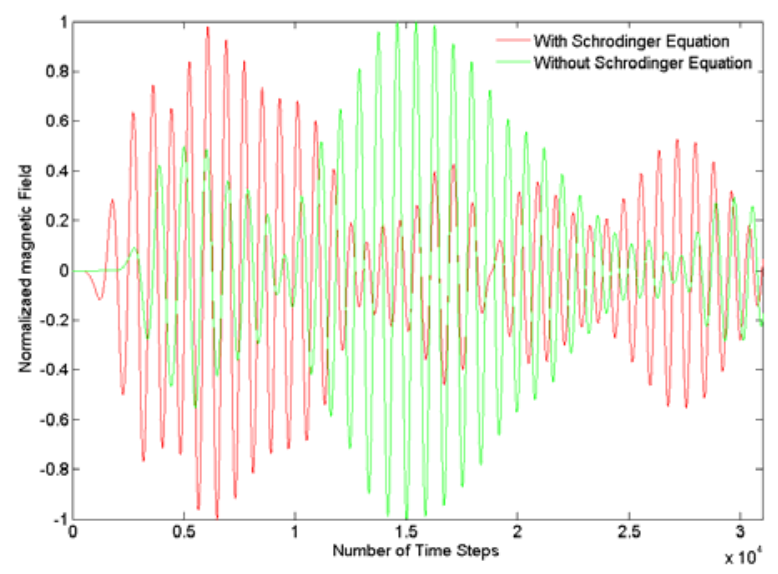

(d)

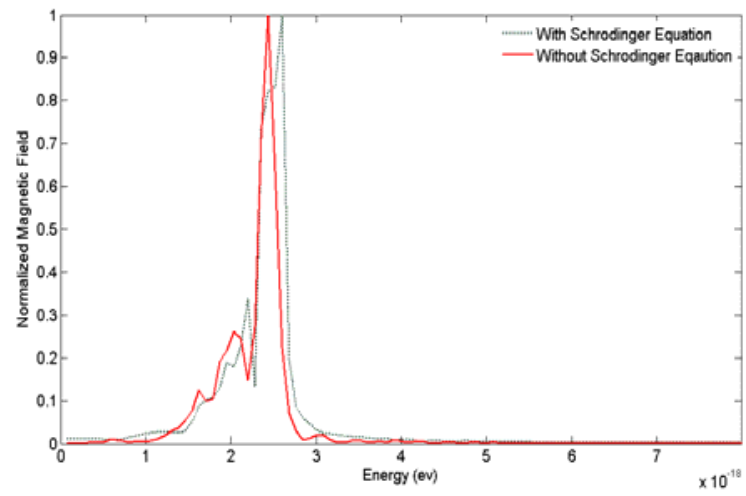

(e)

Fig. 2: (a) Structure for example 1, (b) Field intensity in the $x y$ plane without nanowire (c) Field intensity in the $x y$ plane with nanowire (d) Normalized magnetic field intensity with and without Schrödinger equation (e) Normalized field with respect to energy $(\mathrm{eV})$.

Figure 3(b) show s the $\mathrm{n}$ ormalized electric fie ld i ntensity near the center of the NW, under two different situations, i) the field is e xcited a nd localized betw een nan ospheres at one-end of the NW (from example 1, green color line), ii) the field is ex cited and loca lized at both-ends of the NW (example 2, red c olor line). It $r$ epresents that in the case of resonance fie ld at one end (e xample 1), the field becomes weaker $\mathrm{w}$ ith the pa ssage of time, $\mathrm{w}$ hile in the $\mathrm{c}$ ase of resonance fie ld a t both ends of the $\mathrm{N} \mathrm{W}$ ( example 2), amplitude of field remains stronger for longer time along the 
NW. The reason of stronger field at NW in the sec ond case is due to two sources i.e. at ea ch end of the wire and this causes resonance for longer time.

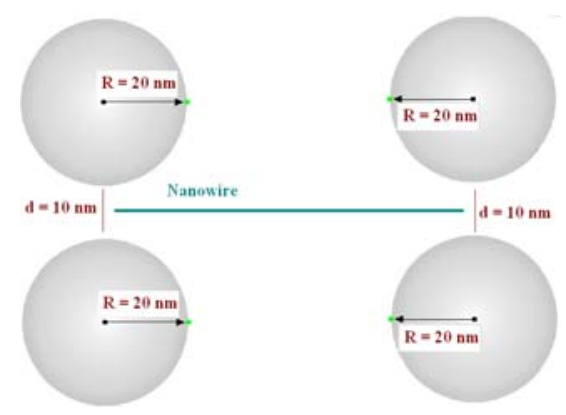

(a)

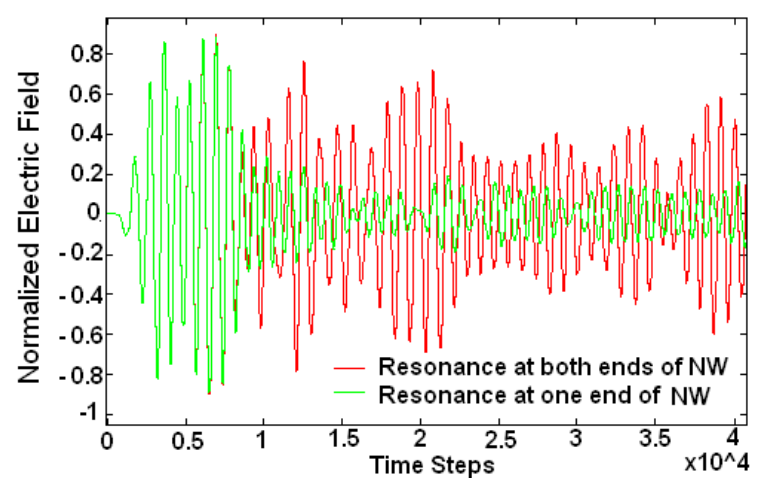

(b)

Fig. 3: (a) Structure for example 2, (b) Electric field at NW with localized fi eld at o ne en $d$ and localized field a $t$ b oth ends of the nanowire.

These struc tures may have num ber of a pplications in different a reas su ch a s b io se nsing, e.g. h eating a nd bl ood sample ana lysis. Beca use of com paratively longer and stronger field oscillations, second example can be used for blood or liquid analysis more effectively as compared to the example 1. Figure 4 denotes the normalized field pattern for structure 3(a). In this case three different excitation sources are used, localized fields at both ends between nanospheres, and third close to the center of the NW. The field pattern in Fig. 4 (a) is captured dur ing the trans ient sta te of the method, where a small value at the center of the NW shows the exc itation of the wavefunction. Figures 4 (b) and 4 (c) show the e lectric an $\mathrm{d} m$ agnetic fiel $\mathrm{d}$ patterns for sa me structure a $t$ st eady s tate res pectively. These fie ld patterns describe th at at st eady st ate most of the field concentrates along the NW. H owever, the fie ld values bec ome w eaker and weaker with the passage of time due to field radiation in the surrounding media. These patterns are captured when the gap distance between the nanospheres is $10 \mathrm{~nm}$.

Nonetheless, the patterns and resul ts a re als o stud ied for variable $d$ istance be tween $n$ anospheres, and o bserved the similar phenomena but with different field intensities. Figure
5 show $\mathrm{s}$ the fiel $\mathrm{d} \mathrm{p}$ lot of $\mathrm{t}$ he struc ture with and $\mathrm{w}$ ithout incorporating the $\mathrm{S}$ chrödinger e quation. $\mathrm{F}$ igure 5 (a) indicates el ectric fi eld i ntensity a t NW wi th respect to number of time st eps, dotte dine sh ows the re sult without quantum ef fect a nd the sol id line with qu antum ef fects. Figure $5(\mathrm{~b})$ ind icates the corresponding va lues of $t$ he electric field with respect to energy $(\mathrm{eV})$.

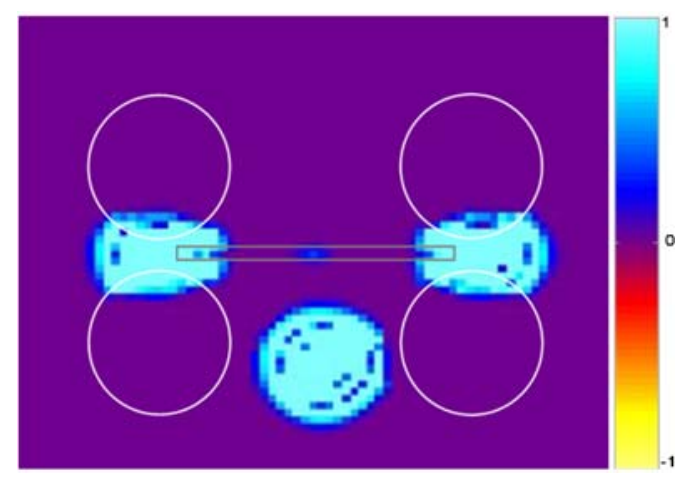

(a)

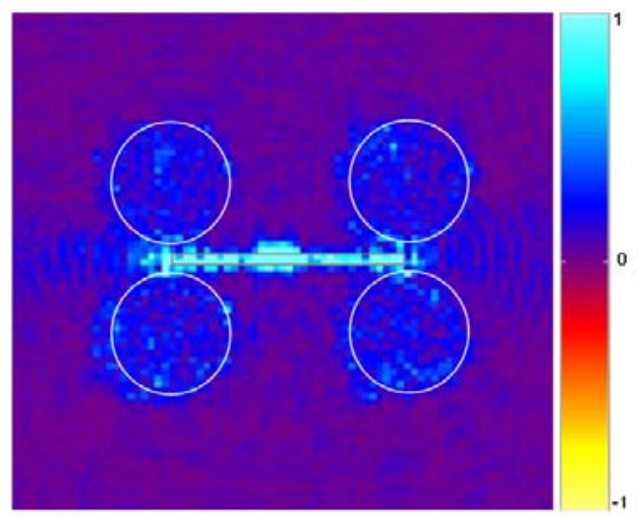

(b)

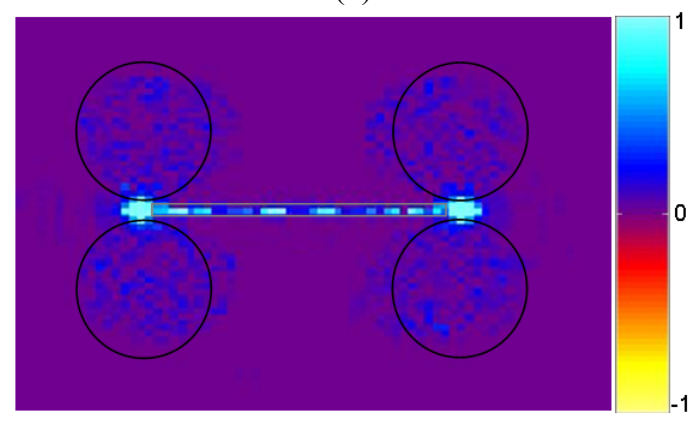

(c)

Fig. 4: Field pattern in the $x y$ plan for structure 3 (a), (a) Field localization at transient st ate between nanospheres at both ends of NW and a third source is below and close to the center of NW (b) Electric fi eld pa ttern at stea dy sta te, (c) Magnetic field pattern at steady state. 
It shows that the dominant mode with quantum effects is at $21.96 \mathrm{eV}$, while without quantum effects is at $22.65 \mathrm{eV}$, and the $\mathrm{d}$ ifference of $0.69 \mathrm{eV}$ is observe $\mathrm{d}$. The se resul ts are observed a $\mathrm{t}$ a po int o $\mathrm{n} \mathrm{N} \mathrm{W}$, w hen the distance be tween nanospheres is $5 \mathrm{~nm}$. This plot sh ows that the fiel $\mathrm{d} v$ alues near to $0 \mathrm{eV}$ with quantum effects is smoother, as compared to the other curve (without quantum effect) that shows some abnormality, and the reason is absence of qua ntum effects. The prop osed a pproach may have po tential a pplications in the fie lds of ac tive nan o-plasmonics, optoelectronics, integration of na no-plasmonis and nano-electronics, a nd nano-sensors.

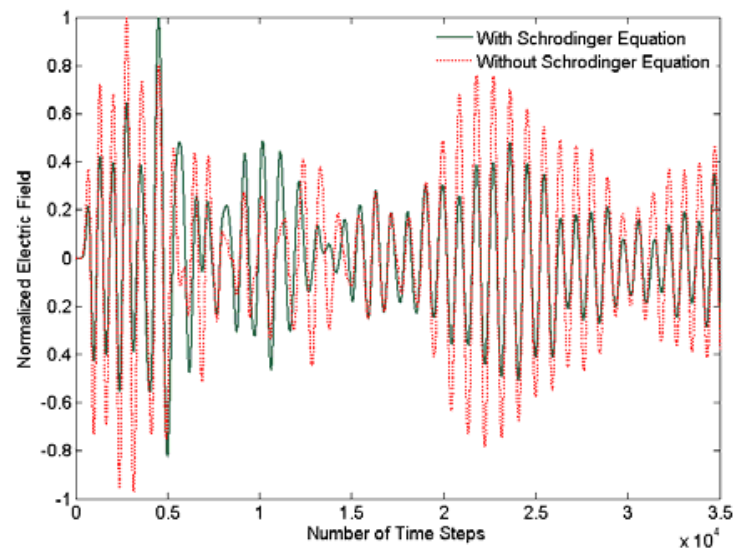

(a)

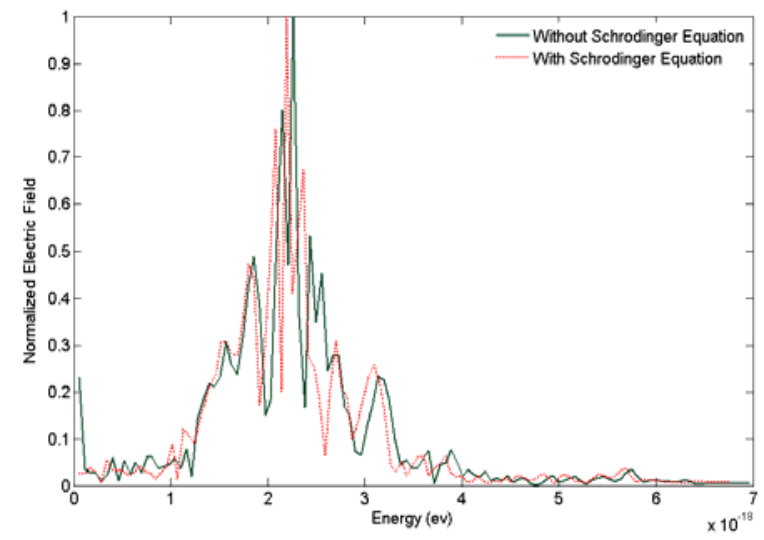

(b)

Fig. 5: Field plot for struc ture 3(a), (a) Ele ctric field with respect to number of $\mathrm{t}$ imes teps wi th a nd wi thout Schrödinger equa tion, b) El ectric fiel $\mathrm{d} w$ ith respec $t \mathrm{t} o$ energy $(\mathrm{eV})$ with and without Schrödinger equation.

\section{Conclusion}

An a pproach th at couples t ime d ependent Schrödinger and LD di spersive model inc orporated Ma xwell eq uations is developed and implemented for plasmonics nanodevices and the FDTD method is applied for ana lysis. The appr oach is applied $t$ o str uctures tha $t$ inv olve $b$ oth dis persive a nd quantum effects. Re sults are compared wi th an $\mathrm{d} w$ ithout quantum effects a nd cle ar difference is obs erved am ong them. $\mathrm{H}$ owever, both a pproaches d id not sh ow an y difference in numerical resul ts for bul $\mathrm{k}$ mat erials. $\mathrm{T}$ he proposed approach pa ves the way for $m$ odeling and simulation of nanodevices in the $\mathrm{w}$ ide spectrum of electromagnetics, and where quantum effects are needed.

\section{REFERENCES}

1. S. A . Maier, Plasmonics: Fundamentals and Applications, 2007, Springer, New York, USA.

2. M. L. Brongersma, P. G. K ik, surface Plasmon nanophotonics, 2007, Springer, The Netherlands.

3. V.M. S halaev and S. K awata, Nanophotonics with Surface Plasmons, 2007, Elsevier.

4. R. Zi a, and M. L. Brongersma, "Surface pl asmon polariton analogue to Young's double-slit experiment," Nature Nanotech. 2, 426- 429, 2007.

5. E. H. Khoo, I. Ahmed and E. P. Li, "Investigation of the light en ergy ex traction ef ficiency us ing su rface mo des in elec trically pumpe d se miconductor microcavity", Proc. SPIE 7764, 77640B, 2010.

6. I. A hmed, E. H. Khoo, O . K urniawan, a nd E. P . Li, "Modeling and simulation of active plasmonics with the FDTD method by using solid state and Lorentz-Drude dispersive model", J. of opt. Society B, Vol. 28, No. 3, 352-359,. 2011.

7. O. Kurniawan, I. Ahmed and E. P. Li, "Development of a palsmonics source based on nano-antenna concept for nano-photonics app lications" IEEE Photonics Journal, Vol. 3, pp. $344-352,2011$.

8. K. F. MacDonald, Z. L. Samson, M. I. Stockman and N. I. Zhelu dev, "Ultrafast ac tive p lasmonics" Nature Photonics, 3, 55-58, 2009.

9. J. A. Dionne, K. Diest, L. A. S weatlock, an d H. A . Atwater, "P las-MOStor: A metal-oxide-Si fie ld e ffect plasmonic modulator," Nano Letters, 9, 897-902, 2009.

10. A. V. Krasavin and A. V. Z ayats, "Three-dimensional numerical modeling of $\mathrm{p}$ hotonics in tegration $\mathrm{w}$ ith dielectric loaded SP P waveguides", Physics Review B, 78, 045425-8, 2008.

11. G. $\mathrm{N}$ aik a nd A . Bol tasseva, "Plasmonics an d metamaterials: lo oking be yond gold and s ilver", SPIE, Newsroom, January, 2012.

12. L. Pierantoni, D. Mencarelli and T. Rozzi, "A new 3-D transmission line matrix sc heme for the $\mathrm{c}$ ombined Schrödinger Ma xwell pro blem in the electronic electromagnetic cha racterization of nanodevices", IEEE Trans. Micro. Theo. and Tech., Vol. 56, N o. 3, 654-662, 2008.

13. I. Ahmed, Li, E. P. and R. Mit tra "A Hybrid Approach for solving coupled Maxwell and Schrödinger equations arising in the sim ulation of n anodevices" IEEE Anten. Wirel. Propag. Letts, Vol. 9, 914-917, 2010.

14. D.G. Swanson, and W. J. R. Hofer, Microwave circuit modeling using electromagnetic field simulation, Artech House Inc. Norwood, MA, 2003. 
15. A. Taflo ve and S. C. Hagness, Computational Electrodynamics: The Finite-Difference Time-Domain Method, $3^{\text {rd }}$ Ed., Artech House, Boston, 2005.

16. I. A hmed, E. K. Chua, E. P. Li, and Z. Chen, "Development of the three dimensional unconditionally stable LOD-FDTD method," IEEE Trans. Antennas Propag., vol. 56, no. 11, pp. 3596-3600, Nov. 2008.

17. D. Raki c, A. B . Djurisic, J. M. Elaz ar and M. L. Majewski "Optical pro perties of Meta llic films for vertical-cavity o ptoelectronic devices" Apl. Optics. 37, 5271-5283, 1998.

18. D. M. Sullivan, Electromagnetic simulation using the FDTD method, 2000, Wiley-IEEE Press 